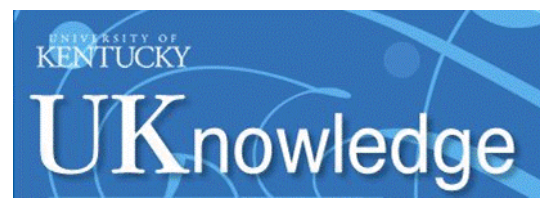

University of Kentucky

UKnowledge

5-1-1995

\title{
The Oral Physician... Creating a New Oral Health Professional for a New Century
}

David A. Nash

University of Kentucky, danash@uky.edu

Follow this and additional works at: https://uknowledge.uky.edu/ohs_facpub

Part of the Dentistry Commons

Right click to open a feedback form in a new tab to let us know how this document benefits you.

\section{Repository Citation}

Nash, David A., "The Oral Physician... Creating a New Oral Health Professional for a New Century" (1995). Oral Health Science Faculty Publications. 14.

https://uknowledge.uky.edu/ohs_facpub/14

This Article is brought to you for free and open access by the Oral Health Science at UKnowledge. It has been accepted for inclusion in Oral Health Science Faculty Publications by an authorized administrator of UKnowledge. For more information, please contact UKnowledge@lsv.uky.edu. 


\section{The Oral Physician... Creating a New Oral Health Professional for a New Century}

\section{Notes/Citation Information}

Published in the Journal of Dental Education, v. 59, no. 5, p. 587-597.

Reprinted by permission of Journal of Dental Education, Volume 59, 5 (May 1995). Copyright 1995 by the American Dental Education Association. http://www.jdentaled.org 
Reprinted by permission of Journal of Dental Education, Volume 59, 5 (May 1995). Copyright 1995 by the American Dental Education Association.

http://www.jdentaled.org 


\title{
The Oral Physician... Creating a New Oral Health Professional for a New Century
}

\author{
David A. Nash, D.M.D., M.S., Ed.D.
}

Dr. Nash is professor and dean, College of Dentistry, University of Kentucky, Internet danashøpopuky. edu

I 1977, Ilya Prigogene won the Nobel Prize in Chemistry for his theory of "dissipative structures," a term that encompasses allopen systems that exchange energy with their environment. His work demonstrated that environmental changes sometimes amplify into disturbances so profound that the system breaks apart, only to reconfigure itself at a higher, more complex level-better able to handle the environ. mental changes. At this "bifurcation point" of breakdown the system undergoes a radical shift. At the level of elementary particles it's a random move. ment; we humans call it a creative choice. Prigogene's work has helped us understand that in our changing world the future is not just out there to be discovered; but we create the future, a better future, at these extraordinary "bifurcation points." It is my judgement that this is a "bifurcarion point" in bealth care in America, and mote specifically and importantly to us, a "bifurcation point" in dental education. It is a point in time when we have the extraordinary potential to reconfigure the profession of dentistry at a higher, more complex level by creating a new oral health professional for a new century ... an oral physician; and by reintegrating dentistry with medicine as a specialty of medicine.

Dentistry emerged and developed as an autonomous health care profession in the United States in the mid-1800s. There were significant reasons for this to occur, including the overwhelm. ing prevalence of oral disease and the few individuals available and interested in treating oral health problems; but conceptually, dentistry is not a discipline distinct from medicine, Rather, dentistry is best conceived as a specialty within medicine. Many, including a significant number of the lay public, understand dentistry as such. However, the education of dentists has been separate and, in many instances, isolated from the education of physicians and other health professionals; and dentistry has remained separate from the general health care delivery system.

Increasingly there are national and international appeals for dentistry and dental education to become more coordinated and integrated with medicine and medical education. The Pew Commission Report on the Health Professions advances the imperative of better integration of education for all health professionals, ${ }^{1}$ Recently, Roger Bulger, President of the Association of Academic Health Centers, challenged the deans of the nation's colleges of dentistry to develop a strategy that would include dentists more directly in the larger health care team and in the reform of the nation's health care delivery system. ${ }^{2}$

National leaders in dental education, re search, and patient care are acknowledging that the trearment of oral disease is increasingly becoming more medical and less surgical. In the January 1994 issue of the Journal of the American Dental Association, Robert Genco, a past-President of the American Association for Dental Research, states: "in the future dentists treating periodontal disease will spend more of their time making diagnostic decisions and writing prescriptions for therapeutic pharmaceuticals. ${ }^{*, 3}$ In the same issoe Burton Edelstein, a board-certified pediatric dentist of New London, Connecticut, says: "Dentistry is gradually moving closer to a medical management approach to dental caries ... similar to other infectious dis. eases. ${ }^{\circ 4}$ In the future of dentistry there will be much less making and doing. Harald Löe, who retired this year as Director of the National Institure of Dental Research, calls for "an increase in the breadth and depth of preparation of future dentists. "That includes "more internal medicine and clinical pharmacology, more immunology, more genetics, and more molecular biology, and new levels of sophistication in communication skills and in clinical decision making. ${ }^{55}$ He calls for the next generation of dentists to be "physicians of the mouth."

Conceptual, biological, epidemiological, professional, and economic forces are converging to suggest that the time bas arrived to address the fragmentation of dentistry from medicine, the sepa. ration of the education of dentists from physicians, and to better integrate dentistry with medicine and the larger health care education and delivery sys. tem. In this paper I will advocate for the creation 
of a new health professional for the twenty-first century, an oral physician. I will characterize the qualities of an oral physician; examine the parados in the changes I am proposing by looking briefly at the history of dentistry in the United States; delineate pressures in the environment that I believe force transformation of oral health professionals to oral physicians; suggest one model for educating an onal physician; advance a list of advantages of such a model; and conclude by challenging you to join in advocating for this paradigmatic shift in dental education.

\section{The Oral Physician}

My selection and use of the term oral physician is meant to emphasize that I am calling for a reintegration of dentistry with medicine and a significant change in the paradigm for educating oral health professionals for the future. If you are troubled by my choice of terms, 1 invite you to substitute "dentist" or "dentist-of-the-future" My argument is that all oral health professionals of the future .... all dentists, will need to be onal physicians, not just a select few:

I begin by advancing the qualities or competencies desirable in an oral physician. I am not suggesting that some of these are not already achieved in our current programs, but I want to be comprehensive in my characterization. The competencies I am proposing are also inclusive of those recommended by the recent report of the Pew Commission on the Health Professions. ${ }^{2}$ Becausc of the specific focus of this paper, I will not attempt to document or specify how an oral physician strategy, such as I am proposing, could or will achieve each of these competencies.

I propose a program to educate an orvl physician that will:

- Create an oral health professional who values people ... motivated to respond to patients, including the culturally diverse, by the ethical imperative of caring.

- Create an oral health professional with a broad appreciation for science, and a deep knowledge of the bio/psycho/social science applicable to clinical and community practice; and with the ability to apply that science to the oral health problems of patients and communities... a professional who thinks and acts scientifically.

- Create an oral health professional with the diagnostic abilities to assess and manage the general health and well-being of patients while receiving oral health care.

- Create an oral heaith professional with a strong grounding in the patho-physiology of the human organism and with knowledge, skills, and attitudes to manage biologically- and pharmacologically. compromised patients in a primary care setting.

- Create an oral health professional with the perceptual motorabilities to skillfully perform the mechano-technical procedures of dentistry.

- Create an oral health professional who is able to communicate effectively.

- Create an oral health professional com. mitted to a life of continued learning ... an intellectually curious person.

- Create an oral health professional committed to serving the public.

- Create an oral health professional who, by education and training, can work effectively in an interdisciplinary way with other members of the emerging health care professional team.

- Create an oral health professional able to assume expanding responsibilities for primary health care in rural and underserved settings, using dental auxiliaries as well as physician extenders, such as nurse practitioners and physician assis. tants,

In addition to these desirable educational out. comes, there are desirable strategic results for the profession of dentistry through moving to the oral physician model 1 am proposing. It will:

- Create an cducational strategy that will take an initial step to reintegrating dentistry into medicine and into the larger health care delivery system.

- Create educational and administrative ef. ficiencies in which dental education can be more cost-benefit effective and less expensive.

- Create an educational program that permits both physicians and dentists to retrain and cross-train, thus increasing flexibility for both groups of profession. als.

- Create a re-awakening of physicians-at. large of the importance of the teeth and the stomatognathic system to general health and well being.

1 am proposing that dentistry as a profession acknowledge that dentists must have the same core understanding of human anatomy, physiology, microbiology, immunology, pathology, and pharmacology and other core basic biomedical sciences as physicians; that the stomatogriathic system is not conceptually different from any other organ system, and that future oral health professionals be educated to the same levels of competency in general medicine as other physicians. I will argue that 
we have construed the basic biomedical sciences both too thinly and too narrowly, and that science. particularly in the context of the "new biology," must be taught more decply and broadly. I will suggest that we must understand that the biomedical sciences for dentistry also include the core of clinical medicine and the management of sick or biologically-compromised patients. I will call for a five-calendar year curriculum in dentistry, with the first three years including the core curriculum of medicine. and the final two calendat years being devoted primarily to the teaching of dentistry.

At Kentucky we have been engaged in inien. sive deliberations regarding an oral physictan strategy with our faculty of the Colleges of Dentistry and Medicine, as well as our University Administration: and we are moving carefully, but persistently, forward in designing and implementing such a program. It will be a program that in five years will result in the awarding of both the Doctor of Dental Medicine (D.M,D.) and the Doctor of Medicine (M.D.) degrees; and a program that we believe will create a new oral health professional for a new era, an oral ploysician.

\section{The Paradox of Change}

The potential reintegration of dentistry with medicine enables us to acknowledge the paradox of change. While we have the sense that at this 'bifurcation point, "moving to an oral physician model will create a new and higher order of things, in some respects we are only returning to our roots; thus the paradox a. moving forward while return. ing. Let me explain by examining the roots of modern dental education and quoting, in a fairly extensive fashion, from the Repotf to the Carnegie Foundation for the Advancement of Teaching by William Gies in 1926 endided Denlal Educalion In The United States And Canada ${ }^{6}$ in his iniroduction to the Report. Dr. Gies comments on the unusual circumstance of dentistry being singled out as a special domain in comparison to the accredited specialties of medicine and the teeth being the only body parts treated in this exceptional context. He suggests this circumstance is due to:

the ancient and mistaken optnions among phystctans ... that dental maladtes were wholly local, and relatively unimportant in their influence on the general health ${ }_{4}$. As a result of these unfounded assumptions... medicine gave little attention to the health of teeth;... the work of repairing or removing teeth as unimportant medically as that of a barber. As a rule, physictans refirained from attempting to render reparative service of this kind, goldsmilhs, jewelers, ivory lurners, umbrella makers, blacksmiths, me. chanics, wig makers, tinkers, engravers, bar: bers, and itinerant jacks-of-all-trades, became the most numerous practitioners of denttstry, which for many years remained a simple trade... he says:

In introducing the history of dental education

Before 1870, improvement in the quality and in the status of dentistry in the United States had long been hindered by the activity of quacks and charlalans. During the fifth decade of the nineteenth century, however, dentistry was steadily raised to the level of a profession by two general lypes of honorable practitioners. The larger group gave attention to dentistry as a trade or as an accessory to unother mechanical vocation. Most of them were uneducated, drawn chiefly from the ranks of craftsmen skilled in the use of small tools and especially interested and adept in the reconstructive phase of den. tistry. They gave earnest and faithful service in useful everyday praclice, but, with a few notable exceptions, contributed little of abiding value to the development of den. tistry, and did practically nothing to promote its educational advancement or its biological improvement.

The smaller group, who were physicians in fact or in spirit, practiced dentislry as though it had been an accepted specialty of medicine, and were usually men of high character, broad intellectual interests, engaging personality, and special influence. Preeminent among those who had originally been general practitioners of medicme, but were led by their apprectations and aptitudes to specialize in dentistry was Chapin A. Harris. Others of the group, among them Horace $H$. Hayden, began their professional work as mechanical dentists, but, realizing the medical import of dentistry, subsequonlly studied medicine to improve their practice of it as a specialty of the healing art

Harris and Hayden ... in 1839 ... suggested that dentistry be taught formally at the University of Maryland, which at the time conststed mainly of a school of medicine; but their proposal was rejected, the medical faculty expressed the opinion that the subject of dentistry was of little consequence and thus justified their unfauorable action' ... When it uras found that training in dent istry could not be developed under medical auspices or in assoctation with medictne, Harris, Hayden, and their associates, accepting the best of the remaining alternatives, established an independent dental school and 
Intliated the development of formal educa tion in dentisiry as a separate system. The first dental school was located in Baltimore, where Harris and Haylen lived, and was named the Baltimore College of Dental Sur: gery. It is significant of the abiding medical purpose of its founders that they named it a college of dental surgery, and based their curriculum on the medical sciences. The founders and firsl faculty named in the char. ter were four Doctors of Medicine (M.D.s) two of whom, also dentists. had recently received the honorary degree Doctor of Dental Surgery from the American Sociely of Dental Surgeons. says:

Gies, in advancing bis recommendations,

recent advances of sctence ... have shown that certain common and similar disorders of the teeth may involve prompt or insidious development of serious or possibly fatal ail ments in otherparts of the body... the import for both dentistry and medicine of these significant findings is obvious. They force the conciuston that dentistry is an impor. lant mode of health service and that in gen. enal it is quite as significant for the maintenance of health as some of the accredted specialties of medical practice. Denlistry should no longer be ignored in medical schools and its main heallh-service fealures should be given attention to the training of general practitioners of medicine ... the practice of dentistry should be made either an accredited specialty of the practice of conventional medicine or fully equal to such a specialty in the grade of health service, (Emphasis added)

Dr. Gies proceeded to delineate some of the barriers that existed for dentistry becoming a specialty of medicine, including medicine's general resistance, the growing demand for dental practitoners that could not be met by medical schools wirhout significant expansion, the rigidity of the medical curriculum, the unyielding views of medi cal state boards and medical educators, and the resistance of dentists themselves.

But Dr. Gies continues his report expressing his preference in this matter by arguing that if dentistry cannot become an accredited specialty of the practice of conventional medicine and if denistry as it is now organized should not wish to become an oral spectalty of medicine, then public interest would ultimately require the creation of a "full bealth service equivalent of an oral specialiy of medicine. "While seemingly acknowledging a theoretical preference for dentistry to become an accreditated specialty of medicine, Dr. Gies con cluded that the level of organization of dentistry in 1926, and the continuing barricrs which existed for integration of medicine and dentistry were such that only the second option, that of becoming an equivalent heaith service, was viable at that point in time. Of interest in our eurrent discussion is in what extent dentistry has become a "full health service equivalent of an oral specialty of medicine:

Clearly, the Gies Report had a significant impact on dental education, and has done for dental education what the Flexner Report of 1910 did for medical education. It eliminated proprietary schools, it moved dentistry into university settings, and it improved the internclationship of medicine and dentistry. But ... the question is: "Has it raised dentistry to the full bealth service equivalent of an oral specialty of medicine?" It is my judgement it has not. That judgement, if valid, forces us to acknowledge the inadequacies of Gies' pragmatic and determinative recommendations, and return to what I believe was his favored theoretical or conceptual view, that dentistry become an acerediced specialty of the practice of conventional medicine.

1 believe analysis and reflection on environmental issues substantiates the vicw that dentistry is not now a full-service equivalent of a specialty of medicine, but current environmental forces are driving the transformation of dentistry to bocom. ing a specialty of medicine. Before pursuing the argument, I note with more than passing interest. that in bis report, Gies argued for an enlarged view of dentistry in which "dental surgeons and dental engineers" become "oral physicians" ... with "oral physician" being Dr. Gies' own terminology.

\section{TRANSFORMATIVE FORCES}

I will attempt to provide justification and rationale for the oral physician and this educational proposal by looking briefly at several environ. mental pressures that are forcing transformation of dentistry. They are conceptual, biological, epidemiological, professional, and economic.

Conceptual reflection forces transformation of dentists into oral physicians. The oral cavity, the stomatognathic system, is a part of the human body. It is not remarkably differcnt than any other functional organ system. There is no reason to believe that the first twenty centimeters of the alimentary canal is or should be treated as conceptually different than the rest of the human body. Cercainly it has unique qualities and characteristics, but they are differences of form and function not substance. Gies' understanding and critique has taken on even new meaning in today's science. He said "Athere is an ancient and mistaken opinion that dental maladies are wholly local and relatively unimportant in their influence on general health "Oral health is intimately related to general health and well-being. Oral health is not elective or 
discretionary. We have also come to understand the oral cavity as a mirtor of health, with many systemic diseases being reflected through oral manifestations. Likewisc, many oral diseases bave systemic effects. The mouth is integrally and intimately linked to the body, Former Surgeon General $C_{\text {r }}$ Everett Koop expresses the concept well in the context of the contemporary health care reform debate, "you're not healthy without good oral health." Oral health is an essential component of general health, human function, and the quality of life. And ... oral health professionals should be able to consider and evaluate the general health of their patients in caring for them, as well as participate in the provision of general health care, in ways no different from other specialties of medicine. Dentistry is to medicine as ophthalmology is to medi. cinc. Conceptually they are equivalent specialties of medicine.

Reflection on the "new biology" forces transformation of dentists into onal physi. cians. Cellular and molecular approaches to diag. nosing and treating disease have revolutionized bealth care in the past decade. Understanding at this lcvel is dramatically expanding our options for prevention, diagnosis, and treatment. To apply modern science, the contemporary dentist must understand modern science in a way current curricula in dental education do not permit. There are significant numbers of individuals who are critical of our current dentists $s^{2}$ education in science and application of science. Bruce Baum, Clinical Director of the National Institute of Dental Research, is exhortative, "progress in biology and medicine is rapid and dental education is not keeping pace. This situation cannot, and should not continue. "7

The science knowledge base required of a dentist managing the oral health or an individual closely resembles that required by a specialist physician managing the health of any other of the body's organ systems. Both must broadly understand buman biology, including biochemical mechanisms, molecular biology, and immunobiology. Use of genetic probes and monoclonal antibodies tô detect diseasecausing bacteria or by-products of disease in oral tissues; pathogen replacement therapy; oral vaccines; molecular engineering, including gene transfer; non-steroidal anti-inflammatory drugs, biological response modifiers, growth factors, and cyrokines to repair tissues; synthetic saliva; these and other techniques of modern science requite that the contemporary oral health professional be comfortably grounded in a sophisticated science base. Bauth is confident that, "maintenance and repair of periodontal, dental, and mucosal tissues by biological (versus surgi(ai) means will be possible within one generation's time, because of advances in connective tissue components, bone inductive proteins, and growth factors, ${ }^{17}$ And, while affirming that the oral physician must be founded in the "new biology, it is imperative to also affirm that the oral physician must be able to continue to provide the same skillful level of complex mechano-technical therapy as in the past.

Epidemiological analyses force transformation of dentists into oral physicians. Mil. lions of Americans who are medically or pharmacologically compromised experience orai health problems. In fact, many individuals are at high risk for oral problems because of systemic disease and disabling conditions, The dentist must be able to manage the oral health care of individuals with diabetes, heart disease, cancer, acquired-immune deficiency syndrome, as well as a myriad of other diseases and processes that require accommodation in oral therapy. Additionally, dentists must understand and accommodate to the increas. ing numbers of medications taken by their patients. A 1992 study in the Journal of the American Dental Associalion ${ }^{8}$ indicates that 40 percent of adult dental patients used medications, most often cardio-vascular agents; and that the numbers of individuals so medicated increases with age. Many of these drugs affect dental therapy, requiring dentists to have a high level of knowledge in physiology, pharmacology, and pharmaco-dynamics in order to make necessary accommodations. The targe cohort of aging individuals who are dentate and who regularly seek dental care intensifics the importance of this issue for dentistry and dental education. Furthermore, many health problems can be compromised without appropriate dental therapy. Failure to treat oral infections can jeopard. ize the oufcome for patients receiving bone marrow and organ transplants, cardiac valvular surgery. joint replacement, or control of diabetes. Additionally, medications or head and neck radiation, by compromising salivary secretions, can create an oral environment that iriggers rapid destruction of the teeth. The success American health care is experiencing in managing disease and disability and extending life has resulted in large numbers of health-compromised individuals seeking routine oral health care from the primary care denlist. The oral pirysictan must be able to effectively and safely provide care to these individuals.

The changing epidemiology of oral disease also forces transformation of dentists into oral physicians. The profile of oral health problems has been changing rapidly and dramatically. Recent studies 9,10 by the National Institute of Dental Re search show impressive gains in the oral health of the American public. A sample of working adults, representing 104 million A mericans, demonstrated that only 4 percent of working adult Americans have lost all of their teeth, and one-half of the sample has not lost more than one tooth. In contrast, 42 percent of all adults over sixty-five years of age are edentulous. Edentulism in America de creased from 7.3 million in 1971 to 3.7 million in 1985. The average American will have five fewer 
missing teeth in the year 2000 than in 1962.

In 1987, one half of American school children had never had a carious lesion or a restoration. This reflects a continuing dramatic decrease from 1980. when a similar survey showed 37 percent of schoolaged children to be caries free. Additionally, the mean DMFS declined in this brief time period from 4.8 to 3.1. Two-thirds of the carious lesions occurring in children occur in the pits and fissures, areas least affected by fluoride, yet surfaces where pit and fissure sealants are effective, when utilized. Increased utilization of sealants by the profession will result in further significant declines in dental caries. "Although caries in all its forms will continue to be seen for some time, the filling of cavities will cease to be the mainstay of general prac tices ${ }^{\text {nl1 }}$ While gingivitis is common among Americans, periodontal health is continuing to improve, with fewer individuals experiencing serrous periodontal disease with its associated increase in the periodontal pocket depth.

The changes in the epidemiology of oral diseases, coupled with demographic shifts in our population, have significant implications for dentistry, and for dental educarion:

- More people, people with relatively good oral health, will be seeking regular dental care, not only to manage oral health problems, but to sustain the oral health they enjoy.

- Restorative services for children will continue to decline, but will increase for older Americans.

- The need for complete denture prosthet. ics will decrease significantly.

- The demand for exodontia services will decline, with the potential exception of third-molat extractions:

- Overall requirements for removable prosthodontic care will decline, with utilization of removal partial dentures being gradually supplanted by increased utiliza. tion of fixed-prosthodontic procedures, and implants, transplants, and replants.

Whilc there will be a strong demand for the services and care offered by an oral health professional, increasingly this will be care that can be provided by auxiliaries, under the supervision of the dentist. The dentist will attend to the more complex and complicated problems of oral health and manage the health and well-being of the patient. George Keller, the well-known strategic planning theorist, has said in several public addresses, "the middle is dropping out in American society, Jobs, and therefore people, are becoming more sophisticated or less so. 12 An assessment of the circumstance in dentistry supports Keller's analysis. Dentistry is becoming both more sophisticated and less so. As a consequence, there is a need to educate future oral health professionals for the more sophisticated dimensions of dental practice in the future, and to be leaders of a team of trained auxiliaries rendering the less sophisticated dimensions of care.

A recent World Health Organization Special Report, "Oral Health for the 21 st Century" says it this way:

The changing disease patterns, the advanced diagnostic and treatment methodologies, and the broadening of responsibilities illustrate the need for a new type of oral health professional someone with spectal education and skills in the care of the oral and maxillofacial complex. These professionals will have principal responsi. bility for oral health care, and they may be assisted by specially trained support person. nel. In addition to these generalist 'oral phos. sictans, it is anticipated that the need will remain for spectalists... it

Analysis of the health professions forces transformation of dentists into oral physi. cians. An appropriate health care delivery system should acknowledge the unique and important role of health for all aspects of the human organism and provide access to care in a cost-effective way, Den. tistry must become fully integrated into the nation's health care defivery system for oral health to receive its justified and equitable share of concern and financing from and for the public. Managed care with its attendant demands for vertical and horizontal integration of providers of care will necessitate that dentistry be an acknowledged dimen. sion of health care, or dentistry will be excluded from financing mechanisms. This acknowledgment can be achieved through a program of education in which dentistry shares a common core with medicine, and dentistry becomes a recognized specialty of medicine.

Contemporary dentists must also be able to expand their role, working cooperatively and effec tively with other health professionals to ensure delivery of primary health care to rural areas, innercity areas, and under-served population groups. Dentists have for many years been acknowledged leaders in promoting primary prevention. In fact. dental offices are places where Americans seek health care most frequendy in a periodic manner, The geographic maldistribution of primary care practitioners, which has resulted in shortages of these individuals in rural and inner-city areas and for under-served populations, forces consideration of oral health professionals expanding their role as primary health providers, particularly in the area of prevention, W. T, Williams, M.D., Senior Vice Presidenf of the Carolinas Medical Center, speaking of dentists practicing in rural areas under-served by physicians says, "T believe it will be incumbent on 
the generalist dentist to bandle more problems in oral medicine than are generally bandled by dentists ... dentists are going to need to expand their roles in otal medicine 13 There is litte doubt that in the practice future of todiy's student dentists the need for care of the common oral diseases will be diminisbed. Dentists of the future will need to expand their role in treating oral cancer, herpes and soft tissue lesions, orofacial pain, temporomandibular joint disorders, dento-facial malalignments, salivary gland dysfunction, and disorders of taste, smell, and swallowing. Additionally, involvement in speech pathology, smoking cessation, and prevention and wellness promotion will require dentists of the future to be oral phystcians. Dentists, while maintaining distinctive roles as dentists, will practice in ways similar to ophthalmologists, that is, managing the health of a specific organ system but maintaining a vital interest in overall health and well-being.

With the changing epidemiology of dental discase, the significant decline in the dentist to population ratio, (the dentist-population ratio peaked in 1987 at $56.5 / 100,000$ and will decline to $43.5 / 100,000$ by 2020 , the lowest ratio since World War I), ${ }^{1 \mathrm{f}}$ and the expanding access Americans have wo oral health care, the contemporary dentist will need to utilize auxillaries in greater numbers and more effective ways. As the need develops to expand productive capacity of dentistry, the most cost-benefit effective strategy will be a sophisticated, welleducated oral beallh professional, the oral physician, lcading a delivery team of auxiliaries, and depending on the proflle of the practice, potentially including physictan assistants and/or nurse practitioners. This goal can best be achieved by reintegrating dental education into medical education; and for dentists to be understood as oral physicians.

Significant shifts are projected in the number of primary care and tertary care physicians in medicine. Nationally, there is arianticipated surplus of physicians generally, and tertiary carc physicians spccifically. Projections range from $165,000^{15}$ to $328,000^{16}$ excess physictans in a fully integrated managed-care environment. The result of this excess will be increased competition, with potential interest by physicians in treating oral disease, parlicularly as dental therapy becomes more biologically and pharmaceutically based. It is reasonable to expect dentists of the present will be less adaptive and competitive in the future environment of health care, particularly as the treatment of oral diseases becomes based in the "new biology, "and less dependent on mechino-technical therapy. When it is possible to treat aspects of oral disease biologically and/or pharmacologically, then other health professionals, those who do not have tradi tional training in dentistry, will become adventuresome, moving into the diagnosis and management of oral discase. An equivalency in knowledge will be essential for the dentist to compete effectively with these other health care professionals. Again, Williams is prophetic conccrning hospital-based dentistry and/or dentistry for the compromised patient, "in the future, the insurcrs will pay those in the oral medicine business who have M.D. de. grees and who can do their own histories and physicals. "13 $\Lambda$ comparable educational program that results in the awarding of a comparable degree ensures a "level playing field" and the ability to compete successfully. The dentist must be able to respond flexibly to these professional enyironmental forces. Bcing an oral phystcian will help ensure expertise to respond to the pressures and tensions among health professionals in the future.

Economic analyses force transformation of dentists into oral physicians. Dental educa. tion must become more cost-benefit effective, Colleges of dentistry are being threatened in the current economic environment of higher education:

- We must renovate or replace our deteriorating clinical and pre-clinical facilities, but have insufficient resources to do so.

- We must invest in developing and retraining faculty, but have insufficicnt resources to do so.

- We must develop and apply informatics to our instructional programs, but have insufficient resources to do so.

- We must increase our credibility for scholarship in our universities through expanding our research, but bave insuffi. cient resources tô dó so.

- We must comply with federal and state regulations to ensure the health, safety, and well-being of our faculty, staff, and students, and their fair treatment, but have insufficient resources to do so.

- We must take action to affirm women and minorities, and must act to embrace and to celebrate the cultural diversity of out pluralistic socicty, but have insufficient resources to do so.

- We must advocate for access, and help provide access to oral health care for our under-served populations, but have in. sufficient resources to do so.

- We must provide Ieadership in develop. ing clinical advances in dentistry, but find ourselves following community-based practitioners because we have insufficient resources to invest in both technology and people.

And with this perceived dearth of resources, dental education continues to be among the most expensive programs of ow nation's universities. Lasi year our nation's 54 dental schools spent (exclusive of sponsored project support) 
$\$ 958,000,000 ; \$ 170,190$ per D.M.D. equivalent graduate, if all post-graduates are included. The mean expenditure per D.M.D. student in 1993-94 was $\$ 49,000$ for all institutions, and $\$ 61, \mathbf{4 3}$ for public ones. ${ }^{17}$ The reduction in public financial support for higher education, coupled with the inability of our students to shoulder increased tuition burdens, demands that we opcrate our programs in more cost-benefit effective ways. Reintegrating dental cducation with medical education offers the potential to effect financial savings and create greater degrees of efficiency for both. This is possible by taking advantage of the substantial infrastructure in medicine in areas such as the basic sciences. student affairs, and administration of education, research, patient care, and public service programs. Additional economies can be realized by a more compact and efficient scheduling of the curriculum in preclinical and clinical dentistry. The oral pinysician proposal can be a more cost-bencfit effective way for universities to educate a contemporary oral health professional.

A further economy has been suggested earlier in analyzing professional forces. As the dentist to population ratio continues to decline, and the demand for care increases, it will be far less expensive to the nation to maintain a stable number of cxten. sively educated oral physicians, supported by an expanding number of trained auxiliaries, to meer the nation's need for oral health care, than to expand the number of dentisis, as was the strategy of the 1960 s and 1970s. An oral physician model, supported with appropriate auxiliaries, is a system that makes economic sense for the future.

\section{Educating an Oral Physician}

Strategies for educating oral physicians will be diverse, depending upon individual colleges of dentistry and colleges of medicine, in many ways not dissimilar from the diversity in programs that exist today, However, key to the oral physician curriculum envisioned at the University of Kenrucky is a five-calendar-year educational program that integrates the curriculum in dentistry and medicine in such a way that it culminates in the awarding of both the Doctor of Dental Medicine (D.M.D.) and the Doctor of Medicine (M.D.) degree. The oral phystcian curriculum anticipated at Kentucky is a curriculum that is problem-driven, competency-based, and results-focused. We must apply our competencies, as means, to problems of oral healtb to achieve results tbat lead to the end or goal of oral health. Our world is changing in ways such that we have new and different problems impacting oral health that old competencies cannot address; and we have new and different competencies that we are not applying to current problems. And ... in all of this, a heightened accountability for cost-effective, high-quality, satisfy- ing results ... that are documentable.

We must structurally organizc our curricula around the problems of oral health and allow prob. lems to drive the curriculum and the teach. ing/learning process. We must specify the human competencies required to be an oral health profes sional, and base the teaching/learning process on these competencies. We must affirm that our ult mate goal is quality care and focus the teach. ing/learning process on helping our aspiring oral health professionals to evaluate results against sci entifically developed standards or criteria of care. It is not my intention, nor would I bave the time or ability, to outine in any detail an oral physictan curriculum or to discuss the various advantages and disadvantages of alternative approaches. However. elements of the curriculum we are considering are:

- Oral physician students would participate fully in the course work of the first three years of the medicine curriculum; through the major clerkship year. Ac Kentucky this cutriculum is progressive and innovative, with extensive use of problem-based learning. This is due to a major grant from the Robert Wood Johnson Foundation as a component of that Foundation's program to reform medical education. Courses specific to dentistry would be conducted during weeks when courses in medicine are not scheduled. Clinical correlations used in the medicine curriculum would include oral health problems for the oral physictan students. At Kentucky it is projected that approximately twelve to sixteen weeks actoss the first three calendar years (or 480 to 640 contact hours), can be used for pre-clinical and clinical teaching of traditional topics in dentistry. Utilization of the medical curriculum should not be construed as an endorsement of the optimum character of that curriculum; continuing reform of medical education is imperative. However, it is an acknow. ledgment that it contains the science, patho-physiology, diagnostics, and therapeutics that are essential to the oral physician; and an acknowledgement of the practical reality of completing such an accredited curriculum to earn the doctor of medicine credential.

- The final twenty-four months (two-calendar years) of the curriculum would be devoted primarily to dentistry with an integrated track of pre-clinical and clinical courses. Currently the dentistry curriculum at Kentucky includes 3,600 contact hours of pre-clinical and clinical instruction. Projected scheduling indicates that instruction in the oral physi- 
cian program could provide equivalent cxposure to dentistry over the five years. However, it is my belief that current curricula require reduction and significant reconstruction.

- The oral physician curriculum with its integration of dentistry and medicine would be designed to meet the accreditation requirements of the Commission on Dental Accreditation and the Liaison Committec on Medical Education. In this model the time allocated specifically to dentistry would be considered as selec. tive hours in the medicine curriculum for fulfilling the requirements for the M.D. degree.

- Oral physician students would be eligible to take Step I of the United States Medical Licensing Examination (USMLE) in June and Part I of the National Dental Boards in July following completion of Year'Two of the curriculum. Step II of the USMLE would be taken in August following the completion of Year Three of the curriculum and just prior to beginning Year Four, the start of the major oral health courses. Part II of the National Dental Boards would be taken in December or January of Year Five of the curriculum. Successful completion of both medical and dental boards would be required for graduation.

- Graduates would be eligible to take state and a regional dental licensure examinatons in June of Year Five. Ability to complete Step III of the USMLE would be dependent on completing an internship year in medicine.

- Oral physician students would be admit. ted to and registered in the College of Dentistry. Courses in the medicine cur riculum would be cross-listed in the College of Dentistry as courses in dentistry. Students would only be eligible to apply for transfer of these credit hours to medi. cine for the awarding of the M.D. degree subsequent to completion of all require ments for the D.M.D. degree.

This proposal for educating an oral physictan should not be confused with previous attempts to educate dually trained practitioners, particularly the stomatologists of some European countries. In that model individuals were educated as physicians with subsequent training in dentistry of very limfted duration and questionable quality. There was no specific attempt to ensure integration and coordination of education. This proposal seeks to integrate and coordinate the education and training of an oral physictan over a five-year time span with the graduate having the diagnostic acumen of the physician and the technical skills of the dentist.

Also, this proposal for educating an oral $p h \psi$ sician should not come as a major surprise to dentistry and dental education. It is the narutal culmination of a trend of converying with medicine that has been occurring over the past 30 years, a trend documented by:

- Increased teaching of the biomedical sciences to student dentists in conjunction with student physicians.

- Increased instruction in physical diagnoSis and oral medicine.

- Increased utilization of hospital-based learning experiences.

- Increased numbers of colleges of den. tistry offering joint D.M.D./M.D. degree programs on an optional basis.

- Increased numbers of oral and maxillo. facial surgery postdoctoral programs combining specialty education with an $M, D$, degrec.

- Increased numbers, and acceptance, of hospital-based general practice residencies.

\section{AdVANTAges}

There are scveral advantages of the oral physician model for dentistry and dental education:

- It results in graduates with deeper and broader education in science.

- It results in graduates with a better understanding of the human organism, and its patho-physiology.

- It results in graduates with more sophisticared diagnostic abilities, and better able to assess and manage the general health and well-being of patients.

- It permits the education and preparation of health protessionals uniqucly qualified to treat the oral health of a growing patient population whose management is more complex, because they are medically and/or pharmacologically compromised.

- It attracts highly qualified students to dentistry, and addresses the complaint of some students regarding the lack of intellectual stimulation associated with current curricula in dentistry. ${ }^{18,19}$

- It results in graduates who are better prepared to participate in interdisciplinary primary health care delivery.

- It permits graduates to be more competi. tive in the future environment of health care, and mote flexible in adjusting to professional changes.

- It responds to increasing national appeals 
for dentistry to become more fully integrated into the health care professional team and the health eare delivery system.

- It provides opportunity for integrating support services for faculty, staff, and students of dentistry and medicine, with resulting efficiencies and economics of scale, and improved cost-benefit effectiveness.

- It is an initial step in dentistry assuming its appropriate position as a specialty of medicine.

There are also advantages of the oral physician model for medical education. The oral physician model:

- Enhances the reaching mission of biomedical science faculty and it improves efficiency and cost-effectiveness, with all medical and dental students being taught in a common curriculum.

- Improves coordination and integration of medicine and dentistry's programs of patient care, biomedical research, health services research, and public and profes. sional service. Sharing leadership be tween dentistry and medicine offers the opportunity to enhance leaderslip gen erally.

- Helps buffer colleges of medicine against the potential loss of resources with the anticipated recommendation for reduction of medical school class sizes.

- It is an initial step in transforming health professions education into a structure where students can enter without being committed to one specific health profes. sion.

Without debate there are potential disadvantages to the oral physician model, some of which can be anticipated now, others only becoming known as the model becomes implemented ... and as the environment contimues to change. Knowing this idea has adequate numbers of detractors and critics, I will remain in the advocacy mode and allow others to postulate problems.

\section{ONE MOMENT IN Time}

I began my comments by drawing on a metaphor from natural science, I conclude by turning to a distinction of philosophy. The German-American philosopher/theologian, Paul Tillich, is a man whose writing is rich in it ability to provoke thinking. Professor Tillich probed the meaning of words and reconstructed them in unconventional ways to challenge our thinking regarding their communicat. tion of understanding. In the context of our discus- sion. I call your atrention to a distinction he draws between two closely related words, both Greek in origin, "chronos" and "kairos." Chronos is the Greek word from which we derive our word time; thus we have cluronology as a way of acknow. ledging a sequence of events occurring through timc. Professor Tillich contrasts "chronos" as time, with "katros"-a concept for the Greeks which is best understood by us as timing. It is the idea of the opportunities of the moment ... the coming together of a number of forces that present a unique opportunity. Tillich frequently refers to "kairos" as the "pregnant moment"-that is, like the time of conception, a particular moment in time filled with extraordinary potential. These moments are for Tillich 'kairotic' moments.

We all acknowledge that there are special moments in time. All time is not the same. Certain moments in time are "bifurcation points," points in time when we can create new and exciting possibilities, 1 will be 50 presumptuous to suggest that this is a period of "kairos" in our society, in health carc, in the profession of dentistry and most specifically in dental education. It is a "pregnant moment; a moment filled with great and special oppottunity. A moment in time when we have the potential to transform the very nature of dental education and the profession of dentistry. A colloquial way of expressing the truth of Tillich's philosophical emphasis is timing is everything. I challenge each of you today to consider the "kairos" of this period and ... at this "pregnant moment" to help conceive a new life for dentistry and dental education. This is a moment when forces are converging to enable us to transform our profession to achieve Gies ideal of dentistry as a specialty of medicine and to address the frngmentation that began over 150 years ago as a result of the forced establishment of a separate and autonomous dental education system. I invite you to share this vision of the dentist as an oral physician and to courageously help effect the transformation, I prod you with the assessment of Eugene Jennings, "the true rebel in a society where change is the only certainty, is the person who resists change!"

\section{Acknowledgmient}

The author acknowledges with appreciation the members of the faculty of the College of Dentistry.and administrators at the University of Kentucky who have had the vision, courage, and commitment to pursuc the oral physictan model for dentistry. 


\section{References}

I. O'Neil BH. Health professions edacalion for the firture schook in service to the nation, Sin Francisco, Pew Health Professions Commission, 1993.

2. Bulgee $\mathrm{RJ}$. Dental ducation and the 21 st Century. J Dent Educ 1993, $57(3): 203.7$.

3. Genco RJ. Phamaceutical and periodontal discase, in a symposium on dentistry's future, its relationship to medicine and tic role of phamaceuticals in dental care delivery. Dooghass, CW, Symposium Editor, I Ani Dent A550c 1994:125:1 1-9, January Supplement.

4. Edelstein BL. The medical management of dental caries. in a symposium on dentistry's future, its relationship to medicine and the role of pharmaceuricals in dental care delivery. Douglass, CW, Symposium Editor, J Am Dent Assoc, 125:31-9, January Supplement, 1994.

5. Loe H. Dentistry in the 21st Century in Simonsen. RJ, Editor, Deutistry in the twenty.first century: A Global Perspective Chicago: Quintessence, 1991, 13-23.

6. Gies WJ, Dental ectucation in the United States and Canada, A report to the carnegie foundation for the advancement of teaching. The Crenegie Eoundation, New York, 1926.

7. Baum B. Has modern biology entered the mouth? The clinical impact of biological researeh. J Dent Edue 1991;55;299:303.

8. Miller CS, Kaplan AL. Guest GF, Catione, JA. Documenting medication use in adult dental patients. J Am Dent Assoc 1992;23:418,
9. Oral health of United States aduits, National Institutes of Health, U. S. Department of Health and Human Services, NIH Publication No. 87 2868, 1987 ;

10. Oral bealth of United States chillren. National Institutes of Health, U,S. Department of Health and Human Services, NIH Publication No. 89-2247, 1989.

11. Oral health for the 21 st Century. World Health Organization, April, 1994.

12. Keller $G$. personal communication.

13. Williams WT, $J_{e}$, Health care refom and ocal medicine.J Deat Educ; 1994 58k-1):319.21.

14. Manpower project, report No. 2, Ancrican Association of Dental Schools, Washington, 1989.

15. Weiner JP. Forecasting the effects of health care reform on U.S. physician workforce requirement, IAMA 273(3):220-34, July, 1994 .

16. Vision of the future, briefing for board members, physicians, and administrators. The Governance Committee of the Advisory Board Company. Washington, D.C., 1993.

17. Annual report on dental education, supplement: analysis of dental school finances, 1993-94, Americsn Dental Association, Chicago, 1994.

18. Neidle, EA, Picozzi, D, Sadowsky, D. Dentists Cum physicians: the implications for dentistry, 1976; 4009 ):595.600.

19. Jacobeen N. Causes and outcomes of disconitnued dental studies, I Dent Edue Press, 1994,58(16)771-74. 